\title{
CrystEngComm
}

Cite this: CrystEngComm, 2014, 16, 2527

Received 6th September 2013, Accepted 8th January 2014

DOI: $10.1039 / c 3 c e 41796 d$

www.rsc.org/crystengcomm

\section{Fabrication of self-assembled peptidomimetic microspheres and hydrogen peroxide responsive release of nicotinamide $\dagger$}

\author{
Suman Kumar Maity, Santu Bera, Arpita Paikar, Apurba Pramanik \\ and Debasish Haldar*
}

\begin{abstract}
The self-assembly of peptidomimetic compounds containing urea and dipicolinic acid was studied to develop a targeted drug delivery vehicle using hydrogen peroxide as a stimulus. Peptidomimetic compound 1 capped with $N, N^{\prime}$-dicyclohexylurea mimicked a peptide turn structure, while compound 2 adopted a rigid planar structure through intramolecular $\mathrm{N}-\mathrm{H} \cdots \mathrm{O}$ and $\mathrm{N}-\mathrm{H} \cdots \mathrm{N}$ hydrogen bonding interactions. The AFM and FE-SEM images revealed that peptidomimetic compound 1 formed microspheres, whereas compound 2 formed a tape-like structure. These microspheres were loaded with the anticancer drug nicotinamide. The microspheres disassembled in the presence of hydrogen peroxide. Hydrogen peroxide ruptured the microspheres composed of peptidomimetic compound 1 , thereby enhancing the proportional release of the loaded drug molecules. The reported peptidomimetic microspheres hold future prospects for use as targeted drug delivery vehicles for cancer cells with high levels of $\mathrm{H}_{2} \mathrm{O}_{2}$.
\end{abstract}

\section{Introduction}

Stimuli responsive intelligent vehicles ${ }^{1}$ are of great research interest in targeted drug delivery and self-healing materials. ${ }^{2}$ Various stimuli such as $\mathrm{pH}^{3}$ ionic strength, ${ }^{4}$ light, ${ }^{5}$ enzymes, ${ }^{6}$ magnetic fields, ${ }^{7}$ ultrasound, ${ }^{8}$ electrostatic interactions, ${ }^{9}$ and temperature ${ }^{10}$ are commonly used for targeted drug release. In recent years biologically available substrates have been used as external stimuli for controlled and localized drug delivery, for example, glucose triggered insulin delivery ${ }^{11}$ and glutathione triggered anticancer drug doxorubicin delivery. ${ }^{12}$ Hydrogen peroxide is a major reactive oxygen species (ROS) in living organisms, and its equilibrium can have diverse physiological and pathological consequences. The mammalian cells produce hydrogen peroxide $\left(\mathrm{H}_{2} \mathrm{O}_{2}\right)$ to mediate diverse physiological responses such as cell proliferation, differentiation, and migration. ${ }^{13}$ There is much emerging evidence which supports that hydrogen peroxide acts as a second messenger in cellular signal transduction ${ }^{14}$ and a

Department of Chemical Sciences, Indian Institute of Science Education and Research Kolkata, Mohanpur, West Bengal 741252, India.

E-mail: deba_h76@yahoo.com,deba_h76@iiserkol.ac.in; Fax: +91 3325873020; Tel: +913325873119

$\dagger$ Electronic supplementary information (ESI) available: Syntheses and characterization of compounds, ${ }^{1} \mathrm{H}$ NMR, ${ }^{13} \mathrm{C}$ NMR, solid state FTIR spectra, Fig. ESI S1-5 and Fig. S1-S11. CCDC 917381 and 951314. For ESI and crystallographic data in CIF or other electronic format see DOI: 10.1039/ c3ce41796d killing agent released by the immune cells. ${ }^{15}$ But the abnormal production of hydrogen peroxide leads to several physiological hazards such as oxidative stress, damage events associated with aging and severe pathologies such as cancer. ${ }^{16}$ Szatrowski and Nathan have established that the human tumor cells produce large amounts of hydrogen peroxide (250 $\mu \mathrm{M}$ in monocytes). ${ }^{17}$ Sobotta and co-workers have used physiologically relevant $\mathrm{H}_{2} \mathrm{O}_{2}$ concentrations (300 nM to $10 \mu \mathrm{M}$ ) over a physiological time span (up to $24 \mathrm{~h}$ ) and compared the impacts of continuous low-dose and one-time highdose treatments. ${ }^{16 h}$ The abnormal accumulation of hydrogen peroxide resulted in oxidative stress which leads to inflammation in tissues (tumor cells) and distinguishes from healthy tissue from tumor cells. Hence hydrogen peroxide can act as a potential stimulus for targeted anticancer drug delivery. Recently there have been a few reports on hydrogen peroxide triggered $^{18}$ delivery of therapeutic substrates via nanoparticles. However, use of the microsphere matrix as a carrier for therapeutic substrates has several advantages over the other delivery systems. ${ }^{19}$ The therapeutic substrates can be dispersed into the core or adsorbed on the surface of the solid macrospheres. ${ }^{20}$

The chemo- and radio-sensitizing agent nicotinamide enhances the tumor blood flow and reduces tumor hypoxia. Niacinamide inhibits poly(ADP-ribose) polymerases (PARP-1), enzymes involved in the rejoining of DNA strand breaks induced by radiation or chemotherapy. Nicotinamide is also used to prevent immunosuppression caused by UVA and UVB 
radiation. ${ }^{21}$ However, nicotinamide may be toxic to the liver at doses exceeding $3 \mathrm{~g}$ per day for adults. ${ }^{22}$ Hence, targeted delivery of the drug is highly recommended.

Recently we have reported the fabrication of mesoporous vesicles from a self-assembled peptide as a drug cargo and a supramolecular double helix capped with Boc and $N, N^{\prime}-$ dicyclohexylurea as a drug carrier. ${ }^{23}$ Herein we report the formation of microspheres by self-assembly of peptidomimetic compound 1 containing dipicolinic acid and two $N, N^{\prime}$-dicyclohexylurea molecules. X-ray crystallography revealed that compound 1 self-assembled to form a supramolecular single helical architecture, whereas compound 2 containing dipicolinic acid and urea self-assembled to form a sheet-like structure. Peptidomimetic compound 1 formed microspheres with diameters ranging from $0.5 \mu \mathrm{m}$ to $2 \mu \mathrm{m}$ from the corresponding methanol-water $(19: 1)$ solution. Hydrogen peroxide ruptured the microspheres composed of peptidomimetic compound 1 . The microspheres were successfully loaded with nicotinamide (also referred to as vitamin $\mathrm{B}_{3}$ ). Hence, hydrogen peroxide can act as a trigger for the targeted and directly proportional release of the loaded drug from the peptidomimetic microspheres.

\section{Results and discussion}

The compounds were designed to mimic the regular turn structure of a tripeptide. Peptidomimetic compounds 1 and 2 containing dipicolinic acid, $N, N^{\prime}$-dicyclohexylurea and urea were synthesized by a conventional solution phase methodology, purified, characterized and studied (Fig. 1). The purpose of incorporating $N, N^{\prime}$-dicyclohexylurea in the reported compounds is to increase intermolecular hydrogen bonding interactions as observed in other urea derivatives and also to enhance the hydrophobicity and crystallinity.

To assess the formation of the self-assembled material, dynamic light scattering (DLS) experiments of peptidomimetic compound 1 were performed. DLS is a rapid scanning method used to identify nanostructures by size distribution. The DLS study shows that peptidomimetic compound 1 forms polydisperse particles with diameters ranging from 0.5 to $2 \mu \mathrm{m}$ (Fig. 2) in methanol-water solution.

The morphology of the reported self-assembled peptidomimetic compounds was studied by atomic force microscopy. The

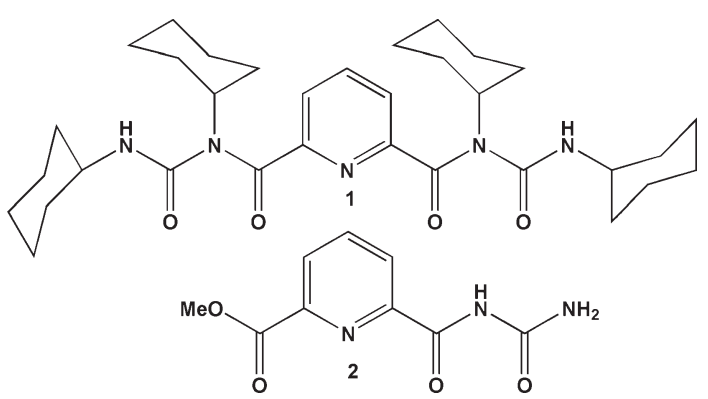

Fig. 1 The schematic presentation of the reported peptidomimetic compounds 1 and 2.

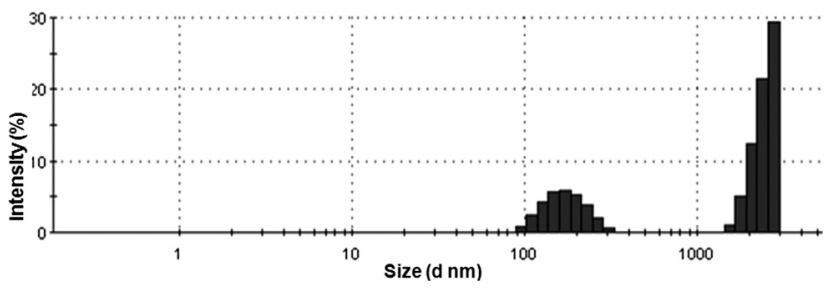

Fig. 2 DLS studies of the peptidomimetic compound 1 self-assembly in methanol-water solution at a concentration of $0.5 \mathrm{mg} \mathrm{mL}^{-1}$.

solution of the reported compounds in methanol-water $(19: 1)\left(0.5 \mathrm{mg} \mathrm{mL}^{-1}\right)$ was drop-casted on a microscopic glass coverslip, dried under vacuum at $30^{\circ} \mathrm{C}$ for 2 days and investigated by AFM. Fig. 3a and b show the polydisperse spherical morphology of compound 1 with diameters ranging from $0.5 \mu \mathrm{m}$ to $2 \mu \mathrm{m}$. The AFM images of compound 2 revealed that the compound adopted a tape-like morphology with a diameter of ca. $200 \mathrm{~nm}$ (ESI, $†$ Fig. S1a).

The morphology of peptidomimetic compound 1 was further studied by field emission scanning electron microscopy (FE-SEM). FE-SEM images of peptidomimetic compound 1 (Fig. 4a and b) showed the formation of polydisperse microspheres from methanol-water $(19: 1)$ solution $\left(0.5 \mathrm{mg} \mathrm{mL}^{-1}\right)$.

Hydrogen peroxide can alter the tight junction composed of proteins and peptides. To investigate the effect of $\mathrm{H}_{2} \mathrm{O}_{2}$ on the peptidomimetic microspheres, the microspheres of compound 1 were incubated with $\mathrm{H}_{2} \mathrm{O}_{2}$. The morphological change of the microspheres after incubation with $1 \mathrm{mM}$ $\mathrm{H}_{2} \mathrm{O}_{2}$ for 5 minutes was studied by AFM and FE-SEM. From
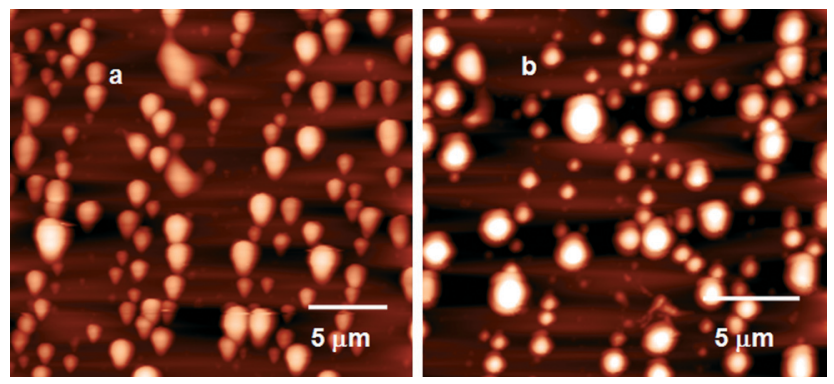

Fig. 3 ( $a$ and $b$ ) AFM images of compound 1 showing the polydisperse spherical morphology.
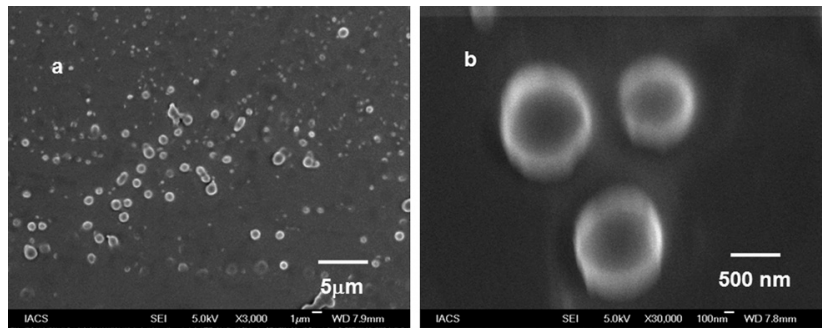

Fig. 4 (a) and (b) FE-SEM images of compound 1 exhibit the formation of polydisperse microspheres. 

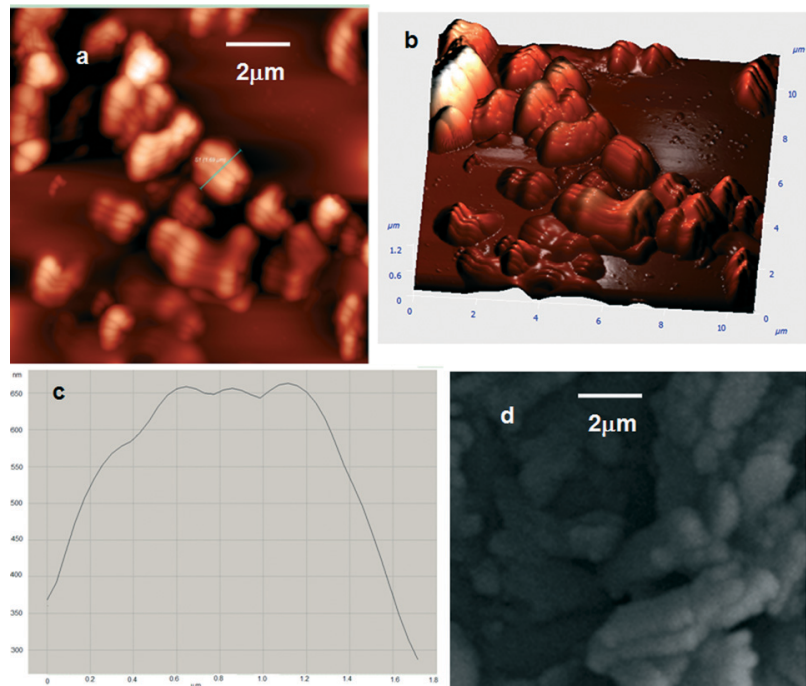

Fig. 5 (a) AFM images of compound 1 microspheres after incubation with $\mathrm{H}_{2} \mathrm{O}_{2} \cdot \mathrm{H}_{2} \mathrm{O}_{2}$ disrupted the microspheres. (b) Topographic view along the $z$-axis. (c) Height profile plot of disrupted microspheres (blue line marked in a). (d) FE-SEM images of disrupted microspheres by $\mathrm{H}_{2} \mathrm{O}_{2}$.

the AFM images it is clear that the spherical morphology of the reported compound 1 was disrupted by $\mathrm{H}_{2} \mathrm{O}_{2}$ (Fig. 5a, b). The height profile plot (Fig. 5c) of the microspheres (blue line marked in Fig. 5a) indicates that the surface is very rough. The FE-SEM image also exhibits the disrupted structures (Fig. 5d). There is no chemical change on compound 1 when treated with $\mathrm{H}_{2} \mathrm{O}_{2}$. The NMR spectrum of the reported compound after stirring with $50 \mathrm{mmol} \mathrm{H}_{2} \mathrm{O}_{2}$ for 48 hours remains almost the same as those of the as-synthesized compounds (ESI, $\uparrow$ Fig. S2). Hence, we can conclude that hydrogen peroxide helps to alter the tight junction composed of the peptidomimetic compound in the microspheres.

The structures of the reported compounds 1 and 2 were also studied by a single crystal X-ray diffraction experiment. A colourless orthorhombic crystal of compound 1 was obtained from ethyl acetate-hexane solution by slow evaporation. ${ }^{24}$ The reported compound 1 crystallized with two molecules in the asymmetric unit (ESI, $\uparrow$ Fig. S3). From the crystal structure it is evident that peptidomimetic compound 1 adopted a 12-membered unusual turn structure (Fig. 6b). A colourless monoclinic crystal of compound 2 was obtained from ethyl acetate solution by slow evaporation. The solid state conformation of compound 2 revealed that it adopted a rigid planar structure through intramolecular $\mathrm{N}-\mathrm{H} \cdots \mathrm{O}$ and $\mathrm{N}-\mathrm{H} \cdots \mathrm{N}$ hydrogen bonding interactions. From Fig. 6c, it is evident that there exist a six-membered intramolecular hydrogen bond between dipicolinic acid $\mathrm{C}=\mathrm{O}$ and urea $\mathrm{NH}$ (N1-H1B ‥O2) and a five-membered intramolecular hydrogen bond between dipicolinic acid $\mathrm{N}$ and urea $\mathrm{NH}(\mathrm{N} 2-\mathrm{H} 2 \cdots \mathrm{N} 3)$.

Moreover, the individual turn-like molecules $\mathrm{A}$ and $\mathrm{B}$ of compound $\mathbf{1}$ are themselves regularly inter-linked one atop another through intermolecular hydrogen bonding interactions ( $\mathrm{N} 10-\mathrm{H} 10 \cdots \mathrm{O} 2$ and $\mathrm{N} 5-\mathrm{H} 5 \cdots \mathrm{O} 5)$, thereby forming a supramolecular helical structure along the crystallographic $a$ a

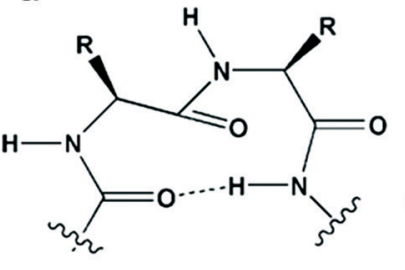
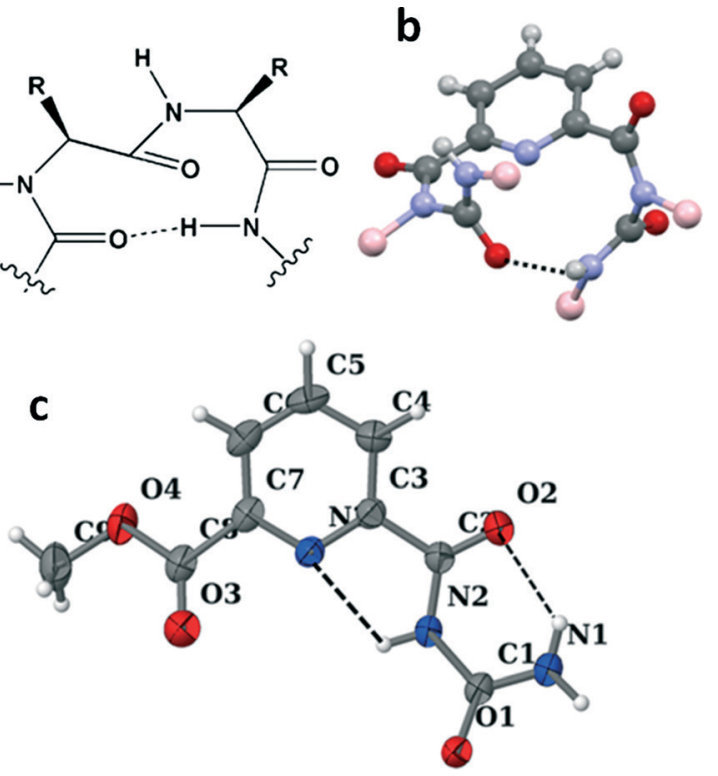

Fig. 6 (a) The schematic presentation of a 10-membered $\beta$-turn. (b) Ball-and-stick model of a 12-membered unusual turn structure of peptidomimetic compound 1. Cyclohexyl groups of compound 1 here appear as pink spheres for clarity. (c) Solid state conformation of compound 2. The intramolecular hydrogen bonds are shown as dotted lines.

direction (Fig. 7). However, in higher order packing, compound 2 molecules are interlinked via intermolecular hydrogen bonding interactions ( $\mathrm{N} 1-\mathrm{H} 1 \mathrm{~A} \cdots \mathrm{O} 1$ and $\mathrm{N} 1-\mathrm{H} 1 \mathrm{~B} \cdots \mathrm{O} 2)$ to form a sheet-like structure along the crystallographic $c$ axis (ESI, $\dagger$ Fig. S4). The hydrogen bonding parameters of compounds 1 and 2 are listed in Table 1.

Previous reports have suggested that the peptidic microspheres have advantages as drug carriers due to their biocompatibility and responsive release. ${ }^{25}$ We tried to load an anti-inflammatory and anticancer drug, niacinamide, with

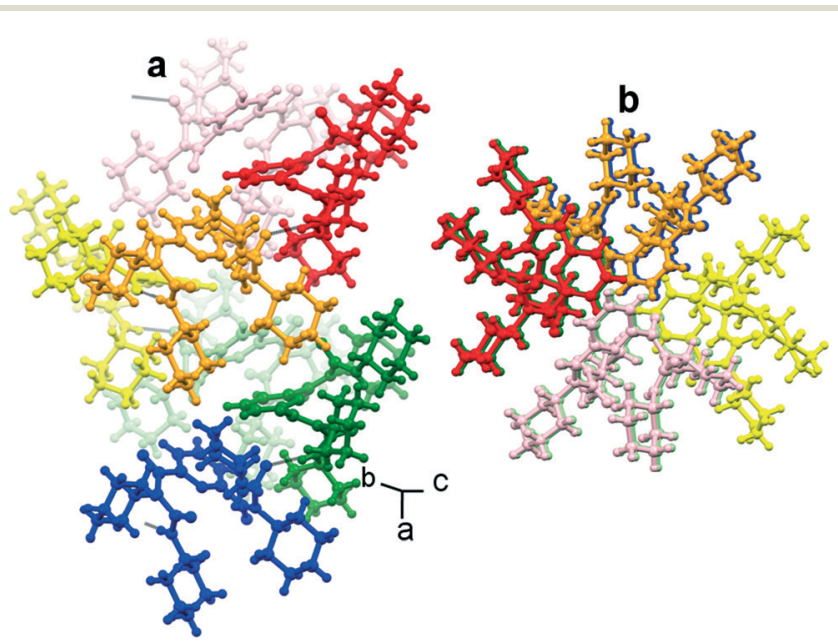

Fig. 7 Ball-and-stick model of the (a) side view and (b) top view of a supramolecular helix obtained from compound 1. Intramolecular hydrogen bonds are shown as dotted lines. 
Table 1 Hydrogen bonding parameters of compounds 1 and $2^{a}$

\begin{tabular}{lllll}
\hline & $\mathrm{D}-\mathrm{H} \cdots \mathrm{A}$ & $\mathrm{H} \cdots \mathrm{A}(\AA)$ & $\mathrm{D} \cdots \mathrm{A}(\AA)$ & $\mathrm{D}-\mathrm{H} \cdots \mathrm{A}\left({ }^{\circ}\right)$ \\
\hline Comp. 1 & $\mathrm{N} 7-\mathrm{H} 7 \cdots \mathrm{O} 8$ & 2.35 & 2.96 & 129 \\
& $\mathrm{~N} 5-\mathrm{H} 5 \cdots \mathrm{O} 5^{d}$ & 2.06 & 2.89 & 166 \\
& $\mathrm{~N} 10-\mathrm{H} 10 \cdots \mathrm{O} 2^{n}$ & 1.96 & 2.82 & 176 \\
Comp. 2 & $\mathrm{N} 1-\mathrm{H} 1 \mathrm{~B} \cdots \mathrm{O} 2$ & 2.07 & 2.72 & 132 \\
& $\mathrm{~N} 1-\mathrm{H} 1 \mathrm{~B} \cdots \mathrm{O} 2^{b}$ & 2.50 & 2.95 & 114 \\
& $\mathrm{~N} 1-\mathrm{H} 1 \mathrm{c} \cdots \mathrm{O} 1^{e}$ & 2.02 & 2.87 & 176 \\
& $\mathrm{~N} 2-\mathrm{H} 2 \cdots \mathrm{N} 3$ & 2.17 & 2.62 & 112
\end{tabular}

${ }^{a}$ Symmetry equivalent positions: $\mathrm{d}=-x, 1 / 2+y, 1 / 2-z ; \mathrm{n}=1 / 2-x$, $1-y,-1 / 2+z ; \mathrm{b}=1-x, 1-y, 1-z ; \mathrm{e}=1-x, 1-y, 2-z$.

the reported microspheres. From the crystal structure of nicotinamide $^{26}$ it is evident that the length of the two longest points of the nicotinamide molecule is $6.791 \AA$. Hence nicotinamide can be loaded into the pores obtained by selfassembly of the reported peptidomimetic compound 1 .

The drug binding efficacy of the microspheres obtained from methanol-water solution of the peptidomimetic compounds was studied by absorption and emission spectroscopy. Compound 2 was not loaded with nicotinamide in methanol-water solution. The fluorescence spectra of compound 1 show that with increasing concentration of nicotinamide, the fluorescence intensity decreases (Fig. 8a). In Fig. 8a, the fluorescence emission is from the reported peptidomimetic compound. In $2.5 \mathrm{~mL}$ solution of the reported compound in methanol, $10 \mu \mathrm{L}$ aliquots of nicotinamide solution in methanol were gradually added and emission spectra were recorded. The decrease in the emission intensity indicates the interaction between compound 1 and the drug. We performed separately the absorption spectroscopic studies with peptidomimetic compound and the control experiment (ESI, $\uparrow$ Fig. S5). The concentration of the drug bound with compound 1 was quantified by UV-visible spectroscopy (Fig. 8b) and the results were expressed as loading efficiency ((amount of drug added - amount of free drug)/ (amount of drug added in \%)). The loading efficiency is $60 \%$. The drug loading content (i.e. (weight of the bound drug/ weight of spheres used) $\times 100$ ) for the spheres obtained from compound 1 is $4 \%$. The experimental procedures described in the experimental section were applied to calculate the loading efficiency and drug loading content.

To investigate the morphological changes of the microspheres after drug loading, FE-SEM experiments were performed. Fig. 9 shows the FE-SEM images of compound 1 after drug loading. From the FE-SEM images it is clear that after drug loading there is almost no change in the size and morphology of the microspheres.

Human cancer cells produce large amounts of hydrogen peroxide. ${ }^{17}$ Hydrogen peroxide is known to alter the tight junction composed of integral membrane proteins and peripheral membrane proteins, ${ }^{27}$ thereby enhancing the permeability of the external molecules. ${ }^{28}$ We used hydrogen peroxide as an external stimulus at different concentrations to disassemble the peptidomimetic microspheres. $5 \mathrm{mg}$ of
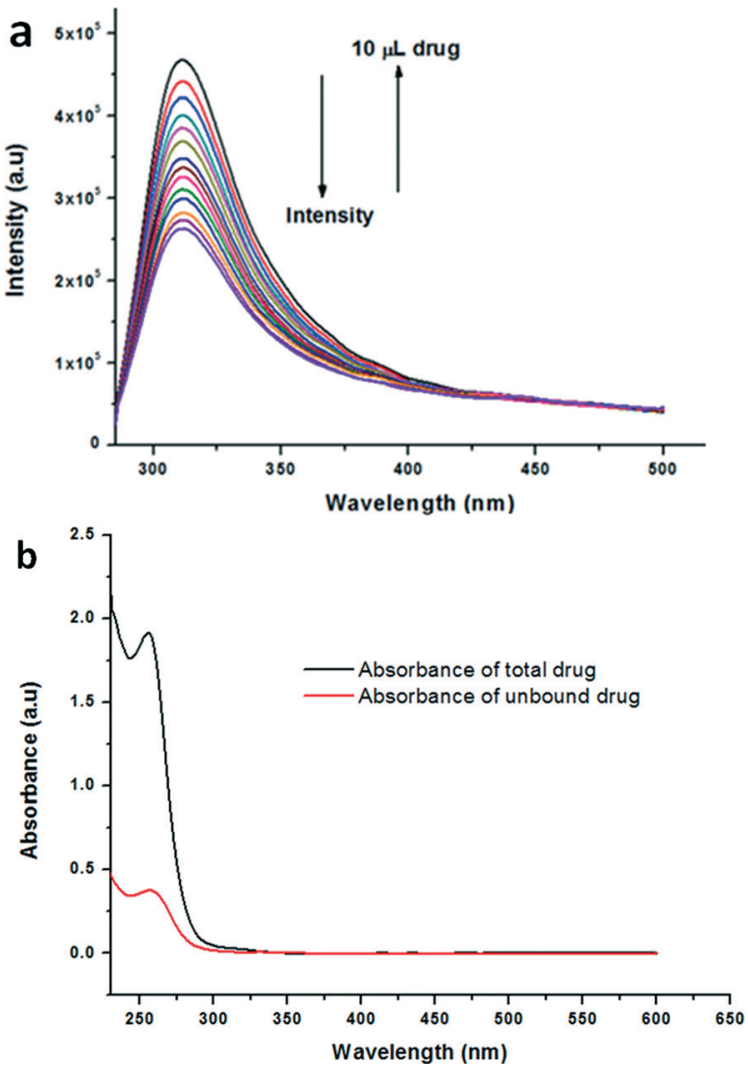

Fig. 8 (a) Emission spectra of compound 1 with increasing concentration of nicotinamide. The excitation wavelength is $270 \mathrm{~nm}$ (compound 1 concentration is $1.5 \times 10^{-4} \mathrm{M}$ and nicotinamide concentration is $1.6 \times 10^{-3} \mathrm{M}$ ). (b) Absorption spectra of the total drug and the unbound drug after drug loading with compound 1 microspheres.

nicotinamide loaded compound 1 microspheres were suspended in $5 \mathrm{~mL}$ water in a $15 \mathrm{~mL}$ centrifuge tube. 30\% hydrogen peroxide was added to the suspension so that the final concentration of $\mathrm{H}_{2} \mathrm{O}_{2}$ in the suspension was $10 \mathrm{mM}$. The suspension was centrifuged at $5000 \mathrm{rpm}$ for 5 minutes. Aliquots were taken from the suspension and monitored by UV-visible spectroscopy at different time intervals. Fig. 10a

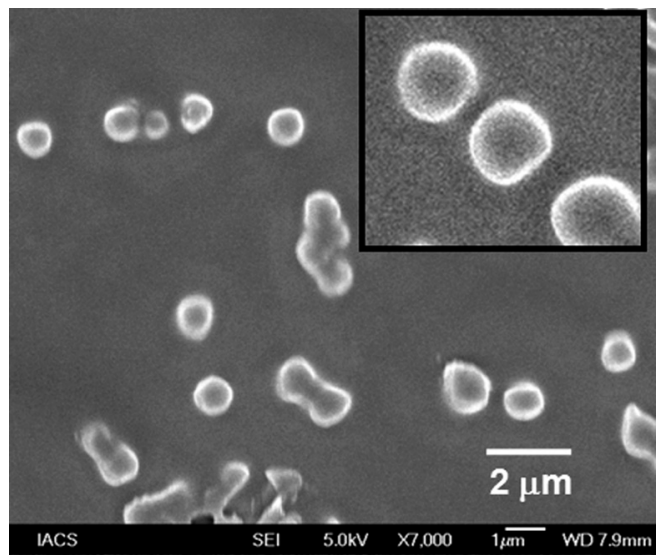

Fig. 9 FE-SEM images of drug loaded microspheres of compound 1. 

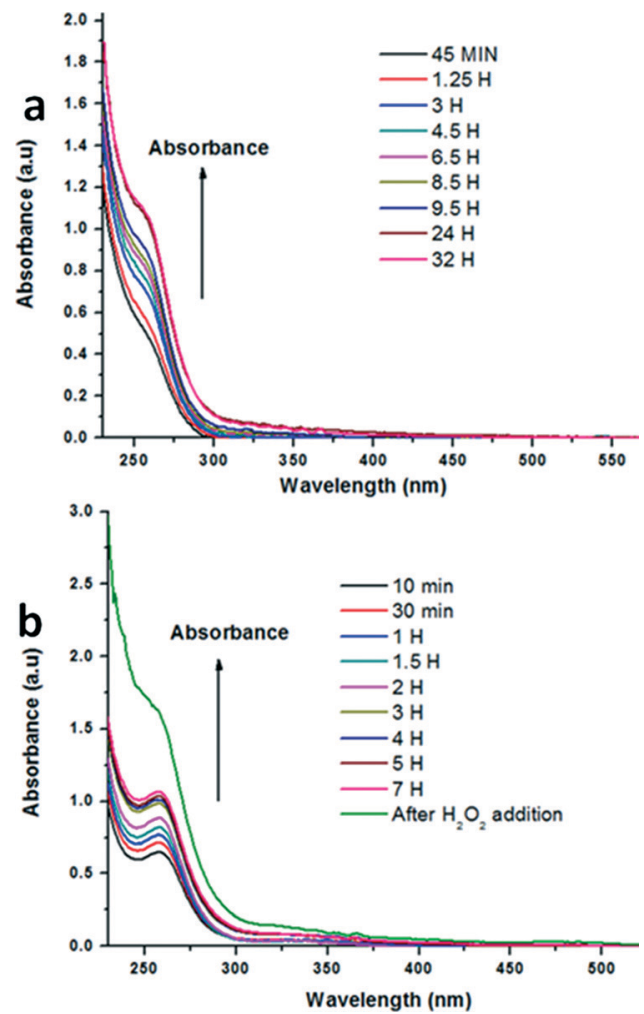

Fig. 10 (a) UV spectra of $10 \mu \mathrm{M} \mathrm{H} \mathrm{H}_{2} \mathrm{O}_{2}$ triggered drug release from nicotinamide loaded compound 1 microspheres. (b) UV spectra of the control experiment with nicotinamide loaded compound 1 microspheres before and after $\mathrm{H}_{2} \mathrm{O}_{2}$ addition.

shows the UV-visible spectra of $\mathrm{H}_{2} \mathrm{O}_{2}$ triggered nicotinamide release kinetics from the nicotinamide loaded compound 1 microspheres. From Fig. 10a it is clear that nicotinamide concentration gradually increases in the aliquot with time and after 24 hours of increasing absorbance saturates, which indicates that no more nicotinamide is released from the microspheres. The control experiment was also done in which $\mathrm{H}_{2} \mathrm{O}_{2}$ was not added to the suspension of the nicotinamide loaded compound 1 microspheres. Fig. 10b shows that without $\mathrm{H}_{2} \mathrm{O}_{2}$ there is an increase in absorbance, although it saturates after 3 hours. However, with the addition of $\mathrm{H}_{2} \mathrm{O}_{2}$ to the same suspension (after $7 \mathrm{~h}$ ), there is a large increase in absorbance by 0.6 units. We conclude that the nicotinamide that has been adsorbed on the surface of the spheres comes into contact with water and shows absorbance initially. After addition of $\mathrm{H}_{2} \mathrm{O}_{2}$, the spheres were ruptured and the loaded drug was released which shows further enhancement in absorbance.

Fluorescence spectroscopy was used to assess the $\mathrm{H}_{2} \mathrm{O}_{2}$ concentration dependence of nicotinamide release kinetics from compound 1 microspheres. Separately $10 \mathrm{mM}$ and $1 \mathrm{mM}$ of $\mathrm{H}_{2} \mathrm{O}_{2}$ were used as external stimuli. The drug release profile for compound 1 with these two concentrations of $\mathrm{H}_{2} \mathrm{O}_{2}$ is shown in Fig. 11 where the intensities at the emission maximum, i.e. $432 \mathrm{~nm}$, are plotted. The excitation wavelength is $270 \mathrm{~nm}$. Fig. 11 reveals that for $10 \mathrm{mM} \mathrm{H}_{2} \mathrm{O}_{2}$ there

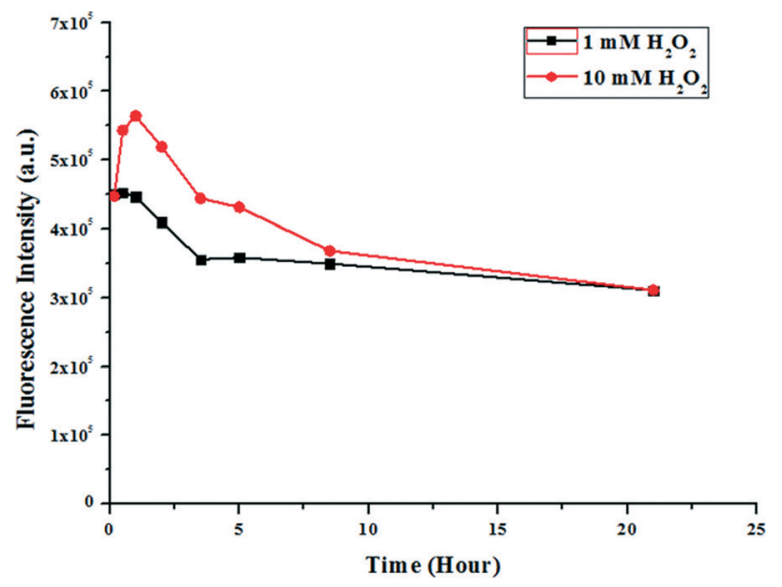

Fig. 11 Drug release profile of nicotinamide loaded compound 1 microspheres obtained from fluorescence spectroscopy using $10 \mathrm{mM}$ and $1 \mathrm{mM} \mathrm{H}_{2} \mathrm{O}_{2}$.

is an increase in the fluorescence intensity for the drug loaded compound 1 microspheres and it has reached a maximum at around 1 hour of incubation. After that the fluorescence intensity gradually decreased and stabilized after 22 hours. Comparing UV-visible and fluorescence spectra it is clear that the fluorescence intensity of nicotinamide decreases with the increase of its concentration in solution.

The initial increase in the fluorescence intensity may be due to the rupturing phenomenon of the microspheres. With $1 \mathrm{mM} \mathrm{H}_{2} \mathrm{O}_{2}$ the effect is smaller, i.e. the increase of the intensity and the slope of the curve are smaller (Fig. 11). Hence, the release of the drug nicotinamide is directly proportional to the amount of $\mathrm{H}_{2} \mathrm{O}_{2}$.

To investigate the morphological changes of the microspheres during drug release by $\mathrm{H}_{2} \mathrm{O}_{2}$, FE-SEM experiments were performed. It may be that the addition of $\mathrm{H}_{2} \mathrm{O}_{2}$ changed the $\mathrm{pH}$ of the solution and caused the disruption of the microspheres and the release of drug molecules. Fig. 12a shows the FE-SEM images of partially ruptured drug loaded microspheres after 15 minutes of incubation with $5 \mathrm{mM}$ $\mathrm{H}_{2} \mathrm{O}_{2}$. Fig. 12b shows the FE-SEM images of ruptured drug loaded microspheres after 22 hours of incubation with $5 \mathrm{mM}$ $\mathrm{H}_{2} \mathrm{O}_{2}$. Since the addition of $\mathrm{H}_{2} \mathrm{O}_{2}$ could change the $\mathrm{pH}$ of the system, a controlled experiment without $\mathrm{H}_{2} \mathrm{O}_{2}$ at variable $\mathrm{pH}$ was performed. However, the vesicles were not ruptured at
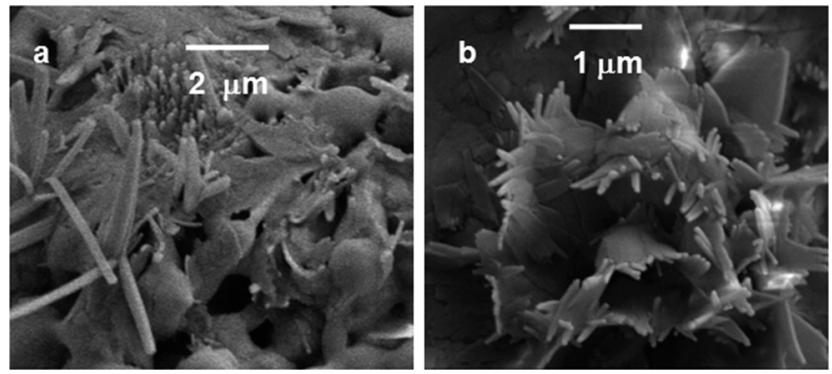

Fig. 12 (a) FE-SEM images of partially ruptured drug loaded microspheres. (b) FE-SEM images of ruptured microspheres. 
$\mathrm{pH} 6$ or even at pH 1 (AFM images, ESI, $\dagger$ Fig. 6). This confirmed that the rupture of vesicles was caused by some $\mathrm{H}_{2} \mathrm{O}_{2}$ specific effect, just not by the change of the $\mathrm{pH}$. The very high concentration and longer time treatment with $\mathrm{H}_{2} \mathrm{O}_{2}$ may have changed the assembly pattern of the reported compound.

\section{Experimental}

\section{General methods and materials}

Pyridine dicarboxylic acid was purchased from Sigma Chemicals while dicyclohexylcarbodiimide (DCC) was purchased from SRL.

\section{Synthesis of peptidomimetic compounds}

The compounds were synthesized by a conventional solutionphase methodology. Coupling was mediated by dicyclohexylcarbodiimide (DCC). The compounds were fully characterized by $500 \mathrm{MHz}{ }^{1} \mathrm{H}$ NMR spectroscopy and $125 \mathrm{MHz}$ ${ }^{13} \mathrm{C}$ NMR spectroscopy, FT-IR and mass spectroscopy. Compounds 1 and 2 were also characterized by X-ray crystallography.

\section{Preparation of the microspheres}

Compound $1\left(0.5 \mathrm{mg} \mathrm{mL}^{-1}\right)$ was dissolved in methanol-water (19:1) solution and was allowed to age for $12 \mathrm{~h}$ at room temperature.

\section{NMR spectroscopy}

All NMR studies were carried out on a Brüker AVANCE 500 $\mathrm{MHz}$ spectrometer at $298 \mathrm{~K}$. Compound concentrations were in the range 1-10 $\mathrm{mmol}$ in $\mathrm{CDCl}_{3}$.

\section{UV-Vis spectroscopy}

UV-Vis absorption spectra of the reported compounds were recorded on a Perkin Elmer UV/Vis spectrophotometer.

\section{Fluorescence spectroscopy}

Fluorescence spectra of the reported compound 1 were recorded on a fluorescence spectrometer (Horiba Jobin Yvon).

\section{Mass spectrometry}

Mass spectra of the compounds were recorded on a Q-Tof Micro YA263 high-resolution (Waters Corporation) mass spectrometer by positive-mode electrospray ionization.

\section{FT-IR spectroscopy}

FT-IR spectra were obtained using a Perkin Elmer Spectrum RX1 spectrophotometer.

\section{Dynamic light scattering}

The particle sizes of the microspheres were determined using a DLS instrument (model ZETASIZER Nano Series Nano ZS) with the compound concentration of $0.5 \mathrm{mg} \mathrm{mL}^{-1}$ in methanol-water (19:1).

\section{Atomic force microscopy}

The morphology of the compounds was investigated by atomic force microscopy (AFM). The solution of the reported compound in methanol-water $(19: 1)\left(0.5 \mathrm{mg} \mathrm{ml}^{-1}\right)$ was dropcasted on a microscopic glass cover slip and dried under vacuum at $30^{\circ} \mathrm{C}$ for 2 days. Images were taken using an NTMDT instrument, model no. AP-0100 in semi-contact mode.

\section{Field emission scanning electron microscopy}

The morphology of the reported compounds was investigated using field emission scanning electron microscopy (FE-SEM). The solution of the reported compound in methanol-water (19:1) $\left(0.5 \mathrm{mg} \mathrm{mL}^{-1}\right)$ was drop-casted on a microscopic glass cover slip and dried under vacuum at $30{ }^{\circ} \mathrm{C}$ for 2 days. The images were taken using an FE-SEM apparatus (Jeol scanning microscope JSM-6700F).

\section{X-ray crystallography}

Single crystal X-ray analyses of the reported compounds were recorded on Bruker high-resolution X-ray diffractometer instruments.

\section{Loading procedure}

$18.5 \mathrm{mg}$ of compound 1 was dissolved in $15 \mathrm{~mL}$ methanol containing $1.35 \mathrm{mg}$ of nicotinamide. The solution was stirred overnight and drop-casted on a Petri dish and dried. Finally, the drug loaded spheres were dried under vacuum and washed with double distilled water (several times) to remove unbound drug molecules.

\section{Calculation of loading efficiency}

First the absorption spectra of $2.7 \mathrm{mg}$ of nicotinamide in $30 \mathrm{~mL}$ methanol were recorded (shown as the black spectrum in Fig. 8b). To the $15 \mathrm{~mL}$ drug solution, $18.5 \mathrm{mg}$ of compound 1 was added and drug loaded spheres were prepared as described above. The unbound drug was washed with $50 \mathrm{~mL}$ double distilled water and the washed solutions were dried in a rotavapour. The resulting solid mass was dissolved in $15 \mathrm{~mL}$ methanol and the absorption spectrum was recorded (the red spectrum in Fig. 8b). From these absorption maxima, recorded before and after drug loading with compound 1, loading efficiencies and drug loading contents were calculated using the equations described above.

\section{Conclusions}

In conclusion, a better understanding of the self-assembly and disassembly processes was achieved which may enhance the control over targeted drug delivery. The reported peptidomimetic compound 1 adopts a 12-membered unusual turn structure and forms a supramolecular helical structure 
in higher order assembly. Compound 1 also forms microspheres from methanol-water solution. The microspheres obtained from the peptidomimetic compound can be efficiently loaded with the anticancer drug nicotinamide. Moreover, hydrogen peroxide helps to rupture the microspheres of peptidomimetic compound 1 which leads to the proportional release of the loaded anticancer drug. Though this is a model "in vitro" experiment with higher concentrations of $\mathrm{H}_{2} \mathrm{O}_{2}$ than under the physiological conditions, this may foster new research for controlled and targeted drug delivery under physiological conditions exploiting high levels of hydrogen peroxide present in cancer cells.

\section{Acknowledgements}

We acknowledge the CSIR, New Delhi, India, for financial assistance (project no. SR/FT/CS-01/2507/11-EMR-II). S. K. Maity and A. Pramanik wish to acknowledge the CSIR, India for the research fellowship. S. Bera and A. Paiker thank the UGC, India for the fellowship.

\section{Notes and references}

1 (a) F. Meng, Z. Zheng and J. Feijen, Biomacromolecules, 2009, 10, 198; (b) M.-H. Li and P. Keller, Soft Matter, 2009, 5, 927; (c) L. J. D. Cock, S. D. Koker, B. G. D. Geest, J. Grooten, C. Vervaet, J. P. Remon, G. B. Sukhorukov and M. N. Antipina, Angew. Chem., Int. Ed., 2010, 49, 6954.

2 A. P. Esser-Kahn, S. A. Odom, N. R. Sottos, S. R. White and J. S. Moore, Macromolecules, 2011, 44, 5539.

3 (a) S. Maity, P. Jana, S. K. Maity and D. Haldar, Soft Matter, 2011, 7, 10174; (b) M. J. Heffernan and N. Murthy, Bioconjugate Chem., 2005, 16, 1340; (c) C. Giacomelli, L. L. Men and R. Borsali, Biomacromolecules, 2006, 7, 817; (d) P. Shi, K. Qu, J. Wang, M. Li, J. Ren and X. Qu, Chem. Commun., 2012, 48, 7640; (e) H. Hu, H. Wang and Q. Du, Soft Matter, 2012, 8, 2816; $(f)$ L. Sheihet, K. Piotrowska, R. A. Dubin, J. Kohn and D. Devore, Biomacromolecules, 2007, 8, 998; $(g)$ J.-Z. Du, X.-J. Du, C.-Q. Mao and J. Wang, J. Am. Chem. Soc., 2011, 133, 17560.

4 (a) J. Naskar, S. Roy, A. Joardar, S. Das and A. Banerjee, Org. Biomol. Chem., 2011, 9, 6610; (b) P. Koley, A. Gayen, M. G. B. Drew, C. Mukhopadhyay and A. Pramanik, Small, 2012, 8, 984.

5 (a) Q. Jin, F. Mitschang and S. Agarwal, Biomacromolecules, 2011, 12, 3684; (b) A. P. Goodwin, J. L. Mynar, Y. Ma, G. R. Fleming and J. M. J. Fréchet, J. Am. Chem. Soc., 2005, 127, 9952; (c) X. Tong, G. Wang, A. Soldera and Y. Zhao, J. Phys. Chem. B, 2005, 109, 20281; (d) Y. G. Jiang, Y. P. Wang, N. Ma, Z. Q. Wang, M. Smet and X. Zhang, Langmuir, 2007, 23, 4029; (e) N.-C. Fan, F.-Y. Cheng, J.-A. Ho and C.-S. Yeh, Angew. Chem., Int. Ed., 2012, 51, 8806.

6 (a) J. Hu, G. Zhang and S. Liu, Chem. Soc. Rev., 2012, 41, 5933; (b) P. D. Thornton, R. J. Mart and R. V. Ulijn, Adv. Mater., 2007, 19, 1252; (c) K. Haba, M. Popkov, M. Shamis, R. A. Lerner, C. F. Barbas and D. Shabat, Angew.
Chem., Int. Ed., 2005, 44, 716; (d) M. Zelzer, S. J. Todd, A. R. Hirst, T. O. McDonalde and R. V. Ulijn, Biomater. Sci., 2013, 1, 11; (e) B. L. Allen, J. D. Johnson and J. P. Walker, ACS Nano, 2011, 5, 5263; $(f)$ J. Hu, G. Zhang and S. Liu, Chem. Soc. Rev., 2012, 41, 5933-5949.

7 (a) S. B. Lecommandoux, O. Sandre, F. Checot, J. RodriguezHernandez and R. Perzynski, Adv. Mater., 2005, 17, 712; (b) M. Krack, H. Hohenberg, A. Kornowski, P. Lindner, H. H. Weller and S. S. Forster, J. Am. Chem. Soc., 2008, 130, 7315; (c) S. Xuan, F. Wang, J. M. Y. Lai, K. W. Y. Sham, Y.-X. J. Wang, S.-F. Lee, J. C. Yu, C. H. K. Cheng and K. C.-F. Leung, ACS Appl. Mater. Interfaces, 2011, 3, 237; (d) Z. Zhao, D. Huang, Z. Yin, X. Chi, X. Wangb and J. Gao, J. Mater. Chem., 2012, 22, 15717; (e) A. Baeza, E. Guisasola, E. Ruiz-Hernández and M. Vallet-Regí, Chem. Mater., 2012, 24, 517.

8 W. Zhou, F. H. Meng, G. H. M. Engbers and J. Feijen, J. Controlled Release, 2006, 116, e60.

9 A. Koide, A. Kishimura, K. Osada, W. D. Jang, Y. Yamasaki and K. Kataoka, J. Am. Chem. Soc., 2006, 128, 5988.

10 (a) A. Castonguay, E. Wilson, N. Al-Hajaj, L. Petitjean, J. Paoletti, D. Maysinger and A. Kakkar, Chem. Commun., 2011, 47, 12146; (b) Z. S. Al-Ahmady, W. T. Al-Jamal, J. V. Bossche, T. T. Bui, A. F. Drake, A. J. Mason and K. Kostarelos, ACS Nano, 2012, 6, 9335.

11 W. Zhao, H. Zhang, Q. He, Y. Li, J. Gu, L. Li, H. Lia and J. Shi, Chem. Commun., 2011, 47, 9459.

12 U. Dembereldorj, M. Kim, S. Kim, E.-O. Ganbold, S. Y. Lee and S.-W. Joo, J. Mater. Chem., 2012, 22, 23845.

13 (a) S. G. Rhee, Sci. STKE 2000, pe1 (2000); (b) M. Sundaresan, Science, 1995, 270, 296; (c) S. G. Rhee, Science, 2006, 312, 1882.

14 (a) Z. A. Wood, L. B. Poole and P. A. Karplus, Science, 2003, 300, 650; (b) H. A. Woo, H. Z. Chae, S. C. Hwang, K.-S. Yang, S. W. Kang, K. Kim and S. G. Rhee, Science, 2003, 300, 653; (c) A. V. Budanov, A. A. Slabina, E. Feinstein, E. V. Koonin and P. M. Chumakov, Science, 2004, 304, 596.

15 (a) E. A. Veal, A. M. Day and B. A. Morgan, Mol. Cell, 2007, 26, 1; (b) R. A. Miller and B. E. Britigan, Clin. Microbiol. Rev., 1997, 10, 1.

16 (a) T. Finkel, Curr. Opin. Cell Biol., 2003, 15, 247; (b) H. Ohshima, M. Tatemichi and T. Sawa, Arch. Biochem. Biophys., 2003, 417, 3; (c) A. M. Shah and K. M. Channon, Heart, 2004, 90, 486; (d) K. J. Barnham, C. L. Masters and A. I. Bush, Nat. Rev. Drug Discovery, 2004, 3, 20; (e) B. C. Dickinson and C. J. Chang, J. Am. Chem. Soc., 2008, 130, 9638; $(f)$ M. T. Lin and M. F. Beal, Nature, 2006, 443, 787; $(g)$ T. Finkel, M. Serrano and M. A. Blasco, Nature, 2007, 448, 767; (h) M. C. Sobotta, A. G. Barata, U. Schmidt, S. Mueller, G. Millonig and T. P. Dick, Free Radical Biol. Med., 2013, 60, 325.

17 (a) T. P. Szatrowski and C. F. Nathan, Cancer Res., 1991, 51, 794; (b) M. L. Lázaro, Cancer Lett., 2007, 252, 1.

18 (a) C. G. Lux, S. Joshi-Barr, T. Nguyen, E. Mahmoud, E. Schopf, N. Fomina and A. Almutairi, J. Am. Chem. Soc., 2012, 134, 15758; (b) E. A. Mahmoud, J. Sankaranarayanan, J. M. Morachis, G. Kim and A. Almutairi, Bioconjugate Chem., 
2011, 22, 1416; (c) D. S. Wilson, G. Dalmasso, L. Wang, S. V. Sitaraman, D. Merlin and N. Murthy, Nat. Mater., 2010, 9, 923; (d) V. V. Khutoryanskiy and N. Tirelli, Pure Appl. Chem., 2008, 80, 1703; (e) K. E. Broaders, S. Grandhe and J. M. J. Fréchet, J. Am. Chem. Soc., 2011, 133, 756.

19 E. M. M. Valle, M. A. Galán and R. G. Carbonell, Ind. Eng. Chem. Res., 2009, 48, 2475.

20 (a) E. Soussan, S. Cassel, M. Blanzat and I. Rico-Lattes, Angew. Chem., Int. Ed., 2009, 48, 274; (b) M. Malakoutikhah, M. Teixidó and E. Giralt, Angew. Chem., Int. Ed., 2011, 50, 7998; (c) R. A. Petros and J. M. DeSimone, Nat. Rev. Drug Discovery, 2010, 9, 615.

21 D. L. Damian, C. R. Patterson, M. Stapelberg, J. Park, R. S. Barnetson and G. M. Halliday, J. Invest. Dermatol., 2008, 128, 447.

22 M. Knip, I. F. Douek, W. P. Moore, H. A. Gillmor, A. E. McLean, P. J. Bingley and E. A. Gale, Diabetologia, 2000, 43, 1337.

23 (a) S. Maity, P. Jana, S. Maity and D. Haldar, Soft Matter, 2011, 7, 10174; (b) S. K. Maity, S. Maity, P. Jana and D. Haldar, Chem. Commun., 2012, 48, 711.

24 Crystallographic data: compound 1: $\mathrm{C}_{33} \mathrm{H}_{49} \mathrm{~N}_{5} \mathrm{O}_{4}, M_{\mathrm{w}}=579.77$, orthorhombic, space group $P 22_{1} 2_{1} 2_{1}, a=11.842(8), b=$ 16.928(12), $c=31.53(2) \AA, V=6321(7) \AA^{3}, Z=8, d_{c}=$ $1.219 \mathrm{Mg} \mathrm{m}^{-3}, T=100 \mathrm{~K}, R_{1}=0.0878$ and $w R_{2}=0.2453$ for 6167 data with $I>2 \sigma(I)$. Compound 2: $\mathrm{C}_{9} \mathrm{H}_{9} \mathrm{~N}_{3} \mathrm{O}_{4}, M_{\mathrm{w}}=$ 223.19, monoclinic, space group $P 2_{1} / n, a=7.1357(5), b=$ 20.7857(12), $c=7.6013(4) \AA, \beta=116.330(3)^{\circ}, V=1010.46(7)$ $\AA^{3}, Z=4, d_{\mathrm{c}}=1.219 \mathrm{Mg} \mathrm{m}^{-3}, T=100 \mathrm{~K}, R_{1}=0.058$ and $w R_{2}=$
0.182 for 2199 data with $I>2 \sigma(I)$. Intensity data were collected with MoK $\alpha$ radiation for compounds 1 and 2 at $100 \mathrm{~K}$ using a Bruker APEX-2 CCD diffractometer. Data were processed using the Bruker SAINT package and the structure solution and refinement procedures were performed using SHELX97. ${ }^{29}$ For compounds 1 and 2 non-hydrogen atoms were refined with anisotropic thermal parameters. The data were deposited at the Cambridge Crystallographic Data Centre with CCDC reference numbers 917381 and 951314 for compounds 1 and 2 , respectively.

25 (a) A. J. V. Hell, M. M. Fretz, D. J. A. Crommelin, W. E. Hennink and E. Mastrobattista, J. Controlled Release, 2010, 141, 347; (b) A. J. V. Hell, C. I. C. A. Costa, F. M. Flesch, M. Sutter, W. Jiskoot, D. J. A. Crommelin, W. E. Hennink and E. Mastrobattista, Biomacromolecules, 2007, 8, 2753.

26 S. R. Perumalla and C. C. Sun, CrystEngComm, 2012, 14, 3851.

27 K. L. Andus and T. L. Raub, Pharmaceutical Biotechnology, Springer, 1993, vol. 4.

28 (a) K. Hashimoto, T. Oshima, T. Tomita, Y. Kim, T. Matsumoto, T. Joh and H. Miwa, Biochem. Biophys. Res. Commun., 2008, 376, 154; (b) G. Schreibelt, G. Kooij, A. Reijerkerk, R. van Doorn, S. I. Gringhuis, S. van der Pol, B. B. Weksler, I. A. Romero, P. O. Couraud, J. Piontek, I. E. Blasig, C. D. Dijkstra, E. Ronken and H. E. de Vries, FASEB J., 2007, 21, 3666.

29 G. M. Sheldrick, SHELX 97, University of Göttingen, Germany, 1997. 